\title{
LA POTENCIA DE LA FICCIÓN EN EL PENSAMIENTO NIETZSCHEANO
}

\author{
Nicolás Di Natale \\ Licenciado en Ciencia Política \\ Facultad de Ciencias Sociales \\ Universidad de Buenos Aires, Argentina.
}

https://doi.org/10.33676/EMUI_nomads.57.07

Resumen analítico.- El presente trabajo analiza las implicancias de la ficción sobre la posibilidad del conocimiento y la razón. Partiendo desde la obra de Nietzsche, se recorrerá las diferentes valencias de la ficción tanto en sus obras tempranas como tardías. En tanto el conocimiento, se partirá de la propedéutica realizada por Kant en La crítica de la razón pura haciendo al distinguir entre el mundo fenoménico y el mundo nouménico. Clarificando la metodología kantiana en la obra citada se puede observar cómo las ideas de la razón poseen una faceta ficcional. En el eje de la Razón como nuevo Dios, emerge la propuesta arkhica de un ordenamiento que es la raíz de la metafísica occidental. La mitologización de la razón, tal como lo menciona Adorno, es la creación de una nueva ficción que da sentido a la existencia. Por ello, la logicización del lenguaje, como lo detecta Cacciari, es la respuesta encontrada por Nietzsche en la propia razón para la formulación de un sentido aprehensible de mundo

Palabras claves: Ficción - Razón - Conocimiento - Mitologización - Arkhé

\section{The power of fiction in the nietzschean thought}

Abstract.- This paper analyzes the implications of fiction on the possibility of knowledge and reason. Starting from Nietzsche's work, the different valences of fiction will be traversed in both his early and late works. Concerning knowledge, it will be based on the propaedeutic realized by Kant in Critique of pure reason, distinguishing between the phenomenal world and the noumenal world. Clarifying the Kantian methodology in the cited work, one can see how the ideas of reason have a fictional facet. Being Reason the new God, the arkhica proposal of an order that is the root of western metaphysics emerges. The mythologization of reason, as Adorno mentions it, is the creation of a new fiction that gives meaning to existence. Therefore, the logicization of language, as Cacciari mentions, is the answer found by Nietzsche in his own reason for the formulation of an apprehensive sense of the world.

Keywords: Fiction - Reason-Knowledge - Mythologization - Arkhé 


\section{Introducción}

El pensamiento perspectivista nietzscheano ha barrido por completo todas las bases sobre las cuales se sostienen los cimientos de la estructura del conocimiento humano. Si el lenguaje ha sido una de dichos pilares fundamentales, en tanto dispositivo de normalización de la pirámide del saber occidental, el acceso al conocimiento ha sido una de las preguntas nodales de la filosofía. Diferentes escuelas han intentado dar una respuesta acabada a la primigenia indagación. Sin embargo, es Kant quien desarrolla una síntesis de los postulados de las corrientes dogmática y empirista, exponiendo una propedéutica de la actividad cognoscitiva. El recorrido kantiano constituyó una línea indeleble que marcó a sus predecesores, volviéndose de esa forma en una piedra angular a la hora de buscar un sentido a la existencia.

Por otra parte, el escrito publicado póstumamente, Sobre verdad y mentira en sentido extramoral constituye una respuesta de parte de Nietzsche a la pretensión humana de aprehensión universal racionalcognitiva. Para el autor alemán, tal vocación se reduce al invento de "unos animales astutos" (Nietzsche, 2016: 619) que terminaron erigiendo sobre sus cabezas un cielo incuestionable llamado Razón-Verdad. Si bien es complejo esbozar un recorrido coherente en la obra de Nietzsche, podemos vislumbrar grandes batallas libradas. Una de ellas está implicada en la destrucción de todo rastro esencialista en el cuerpo del obrar humano. Desentrañar la existencia de un telos y un arkhé, aunque puedan ser necesarios al sentido inexistente de la voluntad de vivir, ha sido la lucha principal del gran pensador alemán. Los límites del conocimiento fueron puestos de antemano por el hombre. Las reglas de la actividad cognoscente pueden variar de acuerdo a la necesidad del 
período de la historia. Si bien hay voces que se oponen a ubicar a Nietzsche por fuera de la historia de la metafísica occidental, entre quienes está Heidegger (2014) y Vattimo (2012), el periplo de su obra fue una crítica encarnizada a quienes cargaron las espaldas de la humanidad con una idea última e inaccesible. De modo que ni siquiera el anuncio de la muerte de Dios (Nietzsche, 2014a; 2014b: 160-162) ha suscitado el comienzo de una etapa sin la existencia de un nuevo fin último: la Razón. En efecto, con ella se trocaron los dogmas eclesiásticos por los científicos. Nuevamente el hombre poseyó una explicación para cada una de sus preguntas y la seguridad necesaria para dar un paso sin el temor de caer en el abismo. Si tratamos de vivir peligrosamente debemos partir desde la perspectiva de que el devenir puede ocasionar dolor y frustración. Sin embargo, ¿̇no es la vigorización de la voluntad de poder activa el privilegio de quitar todo velo a la actividad humana? ¿ $O$ acaso dicha voluntad de poder se traduce en la aptitud para producir tantos velos como sean necesarios?

A los fines de volver productivo el presente planteo se diagraman dos ejes sobre los cuales se aborda la cuestión del conocimiento y la razón en relación a la ficción. En tanto el conocimiento, se partirá de la propedéutica realizada por Kant en La Crítica de la razón pura haciendo al distinguir entre el mundo fenoménico y el mundo nouménico. Clarificando la metodología kantiana en la obra citada se puede observar cómo las ideas de la razón poseen una faceta ficcional. Ayudado por la lectura de Hans Vaihinger (1996) se incorporará la visión nietzscheana de las ficciones como funcionales al desarrollo de la vida. En concreto, el lenguaje puede ser una ficción que vuelve comunicable el mundo. En el eje de la Razón como nuevo Dios, emerge la propuesta arkhica de un ordenamiento que es la raíz de la metafísica occidental. Aquí, el debate metafísico de una razón que destronó el mito para volverse a mitificar (cfr. Adorno, 2007) halla la contrapartida en una propuesta an-arkhica. Valiéndonos de la lectura de Massimo Cacciari, se plantea de forma afirmativa las alternativas nietzschenas al peligro inminente de la inexistencia del sentido de la existencia. La logicización del lenguaje es la respuesta encontrada por Nietzsche en la propia razón para la formulación de un sentido aprehensible de mundo. A su vez el olvido, un dispositivo tanto activo y reactivo, según la funcionalidad cumplida en el campo de la historia y la razón, siendo en este caso la articulación necesaria en la arquitectura de una máscara reguladora. 


\section{1.-¿Conocimiento puro o ficción necesaria?}

\subsection{La propedeutica kantiana}

Kant en La Crítica de la Razón Pura realiza una propedéutica sobre las posibilidades del conocimiento. Solo conocemos por medio de la experiencia, a través de la recepción sensorial del mundo externo. Lejos de ser un empirista, sostiene que la actividad cognitiva depende de la razón, facultad que es enjuiciada mediante la crítica. La razón opera de acuerdo a dos clases de juicios: analíticos y sintéticos. En los juicios analíticos el predicado está contenido en el concepto del sujeto. En tanto razonamiento tautológico no hay posibilidad de incrementar el saber. En cambio, los sintéticos arriban a una solución entre un sujeto y predicado que no están implicados entre sí. Sin embargo, lo novedoso de ésta solución radica en que no existe una intermediación empírica para arribar a la misma, siendo la relación establecida por una intuición que implica $A$ y $B$ estando ambos disociadas a priori. Kant desvía la atención dada a la causa de la fenomenalidad en beneficio de la reflexión acerca de sus condiciones de posibilidad. ¿̇Cómo es posible que un fenómeno me sea dado, en tanto modo de posibilidad de aparecer una aparición? Existe en la fenomenalidad una carga subjetiva, donde ese objeto ya recibió los elementos necesarios para que el sujeto lo haga susceptible de ser conocido. Esa dación es la intuición sensible. Sin embargo, la intuición sin el concepto es ciega, y el concepto sin intuición es vacío. Los conceptos son las categorías tales como substancia y causalidad. La intuición constituye el campo de la experiencia posible, no es un auxiliar del concepto sino que está garantizando la aparición de la fenomenalidad, y no puede salirse de ella. De esta manera, sujeto y objeto se auto-implican de manera indisoluble en el marco de la praxis cognoscente. Existe en la fenomenalidad una carga subjetiva, por consiguiente el tiempo y el espacio son, en efecto, las condiciones apriorísticas de posibilidad del conocimiento. Kant en la "Analítica trascendental" termina de abordar el mundo fenoménico, y deja abierto el interrogante sobre lo nouménico. Finalizado el "sueño dogmático" (Kant, 1999), queda claro que el conocimiento es posible gracias a la dación que el sujeto imprime sobre el objeto, y que no existe posibilidad de conocer sin experimentar. Las ideas de la razón son el fondo invisible que la sed humana de conocimiento anhela descubrir. La existencia de un ente en el orden de lo absoluto es la aventura que invita a Kant a continuar con la investigación de las posibilidades del hombre.

La pregunta que recorre el final de La crítica de la razón pura es: ¿Cómo son posibles los juicios sintéticos a priori en la metafísica? Kant no puede darle un lugar a la metafísica al lado de disciplinas que habitan la isla de 
la verdad, las cuales pueden estructurarse desde la experiencia. La metafísica es "un océano ancho y borrascoso, verdadera patria de la ilusión" (Kant, 2010: 239), donde por momentos se presenta apacible y simula un terreno firme. La razón navega por las aguas de lo desconocido con la pretensión de hacerlas propias. Así como el entendimiento se valía de los juicios, la razón lo hace con los silogismos. La premisa mayor deriva del entendimiento, y la menor de la facultad del juicio. Subsumir lo particular dentro de lo general. A través de ese proceso formal de silogismos se busca la condición incondicionada; lo incausado. Ese camino deriva en la postulación de tres ideas incausadas; Dios, alma y mundo.

\subsection{La ficción de las ideas}

Las ideas de la razón son regulativas. Intervienen sobre el conocimiento estableciendo indicaciones en el tempestuoso mar metafísico. Por ende, nunca debe olvidarse que "el concepto de noúmeno no es más que un concepto límite destinado a poner coto a las pretensiones sensibles" (Kant, 2010: 252). Tal es así, que

la razón humana posee una tendencia natural a sobrepasar ese campo (experiencia); que las ideas trascendentales son tan naturales a la razón como las categorías del entendimiento, si bien con la diferencia de que, mientras las últimas nos conducen a la verdad, es decir la concordancia de nuestros conceptos con su objeto, las primeras producen una simple ilusión, pero una ilusión que es irresistible y apenas neutralizable por medio de la crítica más severa (Kant, 2010: 493).

Kant advierte que uno de los errores en los que puede caer la razón es considerar a la idea como un fin supremo. Si se coloca un principio supremo y último de todo el conocimiento, la razón se torna "perezosa" (Kant, 2010: 519). Ya no impulsará la indagación por el fundamento, pues éste ya lo tiene. El otro error de la razón es estipular un principio teleológico del conocimiento en base a las tres ideas de la razón, lo cual implica creer en el advenimiento de lo fenoménico directamente de lo nouménico. Las ideas de ta razón son bandas elásticas dentro de las cuales se van incorporando diferentes conceptos. Ahora bien, si quisiéramos conocer esas bandas inevitablemente caeríamos en errores. Se las puede pensar pero de ninguna manera conocer. Las ideas operan en una "filosofía del como si"".

1

Hans Vahinger tituló de esta forma Philosophie des Als Ob a su obra más 
Como se mencionó anteriormente, estas ideas constituyen solamente un marco regulatorio siendo ficciones que cumplen una tarea heurística. Ahora bien, que tales ideas de la Razón están fuera del alcance del conocimiento (vale aclarar: de conformidad con los postulados kantianos), no implica soslayar su valor en el proceso cognoscente. Aquí es donde cobran importancia los puntos de contacto con el pensamiento nietzscheano que venimos anticipando. La idea de Dios es un fundamento al cual si se lo quiere describir y determinar, esto es, conocer, se cae en inevitables errores. Kant estipula a Dios como una ficción que ordena la totalidad del conocimiento del mundo interno (Alma) y el mundo externo (Mundo). Cuando Kant se refiere a la "cosa en sí" está dando un fundamento último en el plano de la Realität. A diferencia de Platón, Kant considera que las ideas de la razón solo pueden ser pensadas y más nunca alcanzadas. Hay una relación asintótica con dichas ideas ficticias.

\subsection{El lenguaje ficción del mundo humano}

Podemos afirmar que la ausencia de un fundamento último implica pensar la existencia de la inexistencia de un sentido de la vida, en tanto ese sentido sólo es regulativo ante la pasividad del transitar humano. Nietzsche no hubiera estado tan alejado de Kant de haber leído en profundidad la Crítica de la razón pura. Tal como lo menciona Cragnolini, Nietzsche accedió al pensamiento kantiano a través de La Crítica del juicio y leyó un resumen de Kuno Fisher sobre La Crítica de la razón pura. Es decir que no tuvo una lectura pormenorizada de la obra cumbre de Kant, y quizás por eso fue un crítico tan despiadado de éste. La conexión entre la ficcional función de las ideas de la razón y la ficcionalidad de las actividades humanas es una interpretación contemporánea, válida y afín a la des-absolutización del acceso al conocimiento último.

Si es, como afirma Nietzsche, que "el intelecto no tiene misión alguna fuera de la vida humana" (Nietzsche, 2016: 619) y todo lo que surge de él está amparado por la necesidad de volver codificable el mundo que habitamos, entonces el conocer es una actividad ficticia y un medio de autoconservación del que el hombre se vale para protegerse. Así como el tigre posee dientes y garras afiladas para defenderse, el hombre tiene la palabra y la capacidad de crear con ella diferentes mundos.

En consonancia con lo antedicho, la palabra es "Ia reproducción de

reconocida. Aunque en español sólo se ha traducido una parte de ella bajo el nombre de "La voluntad de ilusión en Nietzsche". 
sonidos articulados de un estímulo nervioso" (Nietzsche, 2016: 621), lo cual implica que no hay una causa fuera del hombre generadora de lenguaje. Nietzsche continúa " $U n$ estímulo nervioso extrapolado en primer lugar en una imagen! Primera metáfora ¡La imagen transformada a su vez en un sonido articulado! Segunda metáfora" (Nietzsche, 2016: 621). El hombre está atravesado por metáforas en la ficción diaria que implica darle sentido con palabras a la existencia. La búsqueda del sentido de la vida ha llevado al hombre a ser un arquitecto de grandilocuentes castillos conceptuales. Una palabra se convierte en concepto cuando perdió la situacionalidad en la cual fue utilizada originariamente y por ende, es particularizada en dicho acto para ser reutilizada en diferentes situaciones similares. Universalizada la palabra pierde la particularidad temporal originaria. Esa pérdida es la igualación de lo no-igual. La diferenciación entre palabra y concepto es una inversión del pensamiento de Schopenhaver, para quien los conceptos sólo pueden ser pensados (como las ldeas de la razón) no estando sujetos a la experiencia pero sí sus efectos. Las palabras, instrumentos de la experiencia, son signos convencionales al servicio de la comunicación. Igualar escamoteando la desigualdad es el principio regulador de la arquitectura del lenguaje. No existe una cualidad oculta inmanente al ente descripto. Los adjetivos utilizados a los fines de elaborar un concepto son palabras con un nacimiento forzoso de igualación de lo no-igual. La fuerza igualadora del lenguaje consigue neutralizar las desigualdades agrupando entre grandes muros conceptuales a todo aquello que presenta una fisonomía parecida.

Sólo "conocemos en realidad lo que nosotros aportamos, el tiempo, el espacio, es decir, relaciones de sucesión y números" (Nietzsche, 2016: 626). Aquí existe cierta cercanía a la teoría del conocimiento kantiana, donde el sujeto pone las categorías para hacer aprehensible la coseidad de la cosa. La dación hace posible el acontecer de la fenomenalidad. Se produce una carga subjetiva en el objeto dejando a un lado la posibilidad (si fuera posible) de apreciar la esencia y nos quedamos con los elementos puestos por el sujeto. Nietzsche reconoce ${ }^{2}$ tanto al tiempo como al espacio como las categorías inescrutables a la dación del objeto.

"Esa creación artística de metáforas con la que comienza en nosotros toda percepción presupone ya esas formas, es decir, se realiza en ellas;

2

Sería una tergiversación imperdonable abordar esa perspectiva asimilando la noción del sujeto de conocimiento entre ambos pensadores. Nietzsche elimina la posibilidad del sujeto 
sólo partiendo de la firme persistencia de esas formas primordiales se explica la posibilidad de que, posteriormente, a partir de las metáforas mismas se constituye el edificio de los conceptos" (Nietzsche, 2016: 627).

La cita deja evidenciado el espiral ficcionado del conocimiento humano; se comienza con una metáfora que moldea el fenómeno, y en la continuidad de esa fenomenalidad se llega al concepto. El mundo está en constante devenir y ante esa evanescente perplejidad se le impone "un mundo del ser, en el que todo aparece redondo y completo" (Vahinger, 1996: 45), plagado de antagonismos. Es decir, el conocimiento es producto de la oposición. La imposibilidad de conocer "la cosa en si" desenvuelye diferentes dispositivos que intentan recrear convicciones dicotómicas. La cosmovisión platónica-judeo-cristiana-occidental se vale de un sistema antinómico donde "el pensamiento depende del lenguaje, y el lenguaje ya está lleno de presupuestos falsos" (Vahinger, 1996: 57). Nietzsche nos invita a extrañarnos de la concepción del término "falso". Cuando se afirma la falsa idea de totalidad no se pretende esgrimir la posibilidad de una idea de totalidad verdadera. El revolucionario pensamiento nietzscheano borra las fronteras del antagonismo. Solamente hay ilusiones, y las mismas mutan ante la necesidad del ser situacional. La inmutabilidad de la cosa es una necesidad del pensamiento humano ante la caótica empresa de establecer un terreno apacible.

Por lo tanto, "nada es más falso que afirmar que nosotros a través del lenguaje designamos las cosas en el mundo" (Nietzsche, 2017: 812). El lenguaje nace como obra artística inconsciente en el hombre, y en él no se nombra al mundo bajo la esencia de cómo se presenta, sino que va de imagen en imagen haciendo una metáfora de otra metáfora. Es imposible la descripción de la Realität por medio del lenguaje. Y aunque probablemente el origen del lenguaje esté más cercano a lo instintivo, la razón le dió un hogar y determinadas reglas para ser una ficción donde hallar el nombre de lo perceptible. Por ello, "la función que desempeñan las ficciones en la misma filosofía de Nietzsche: representa un intento provisorio, una suerte de error útil que luego debe ser abandonado" (Cragnolini, 1998: 54). Ahora bien, si en el lenguaje no se nombra al mundo bajo la esencia de cómo se presenta, cabría preguntarse żacaso es que hay una tal esencia a ser nombrada? ¿̇xiste una tal Realität designable? $\dot{\imath} \mathrm{O}$ acaso es como Nietzsche sostiene que "el mundo aparente es el único: el mundo verdadero no es más que un añadido mentiroso" (Nietzsche, 2010: 52)? Las interrogantes son tan insondables como contundentes en su evanescencia, pues uno no podría dejar de decir, sin por ello romper afinidad con el propio Nietzsche, que nada hay más verdadero que afirmar que con el lenguaje designamos el mundo. 


\section{2.- ¡Dios ha muerto, viva dios!}

\section{1-La mitificación de la razón}

En el siglo pasado quizás no exista otra corriente intelectual que haya cuestionado tan sagaz y vorazmente el proyecto de la modernidad como la Escuela de Frankfurt. Siendo justos, las hüellas del legado frankfurtiano nos permiten hoy reflexionar acerca del presente con una perspectiva del pasado menos historicista y segregada. A su vez, la prognosis planteada sobre el pronto deceso del llamado siglo XX corto implicó la restitución del marxismo al campo del pensamiento. Lejos de reiterar las vicisitudes de la emergencia reflexiva, el cuestionamiento a la autodenominada marcha inexorable del progreso ha sido una luz entre las nubarrones del optimismo decimonónico.

El pensamiento intempestivo nietzscheano irrumpió en los ropajes de los frankfurtianos. La dialéctica de la ilustración estaba en camino a la destrucción de la humanidad en nombre de la misma. El horror que sería inevitable respondía a una apertura del campo de batalla en el siglo pretérito, y éste iba a resonar en una corriente que en apariencia se encontraba en las antípodas del pensador alemán. Ya adelantaba Nietzsche

que la humanidad no marchaba por sí misma por el camino recto, que no es gobernada en absoluto por un Dios, que, antes bien, el instinto de negación, de la corrupción, el instinto de décadence ha sido el que ha reinado con su seducción, ocultándose precisamente bajo el manto de los más santos conceptos de valor de la humanidad (Nietzsche, 2017: 111).

Con esta cita se hacía alusión a un instinto de negación de la vida en tanto construcción de unidades de sentido. La denuncia nietzscheana estaba dirigida a la sentencia de la "muerte de Dios" y con ello el desconcierto de la humanidad.

Pero mejor sería hacer una genealogía a los fines de ubicar el devenir de las estancias nietzscheanas al respecto de la razón. Ante todo resulta paradójico que la misma sea calificada como el triunfo de la humanidad ante el caos de la polivalencia mítica. Ello por varios motivos. En primer lugar, la acusada polivalencia mítica carece de fundamentos serios. Toda construcción mítica dispone de un férreo orden, al interior del cual se establece un juego de relaciones y concepciones que prefiguran la 
existencia. En segundo lugar, acordamos con quienes sostienen que el mito no constituye una representación simbólica de la realidad sino que, por el contrario, se trata de una herramienta de la consciencia humana para la comprensión del sentido de la vida. Es, de esta manera, una verdadera praxis creativa-cognoscente. Todo ello no impide, desde ya, la existencia de un arkhé determinado y congruente con el tiempo histórico al cual remite. Sobre la base de tales consideraciones, entonces, podemos afirmar que el mito no es sustancialmente diferente a la razón. Más aún, que la razón moderna no es otra cosa que la nueva deidad responsable de la transvaloración de un orden, otrora abiertamente mitificado. Teniendo en cuenta, que la misma es un irrupción denominada como el "triunfo" de la humanidad ante el caos de la polivalencia mítica. Al respecto, podemos mencionar lo señalado por J.P Vernant y W. Burkert citados por el Dr. García Gual, a propósito del antiguo panteón griego. Éste, sostienen los autores, "ha de ser visto como un sistema organizado que implica relaciones definidas entre los dioses, como una especie de lenguaje en el que los dioses no tienen una existencia independiente, de igual modo que las palabras en la lengua" (García Gual, 2007: 60). Hay una clara analogía entre el lenguaje y la mitología como juego de oposición. La identidad oposicional es la historia de la metafísica occidental y puede encontrar el hogar en el panteón mitológico. Como los conceptos y la mutabilidad de los mismos, los mitos fueron convirtiéndose y transfigurando la funcionalidad a través del paso de generación en generación. El devenir transita por todo organismo vivo y no deja estable nada a su paso. Ese temor ha llevado a los hombres a construir las murallas más altas para apartarse de la invasión del devenir.

Como bien mencionan Adorno y Horkheimer, el proyecto de la llustración "ha perseguido desde siempre quitar a los hombres el miedo y convertirlos en señores" (Adorno, 2009: 19). Tanto la adversidad como la fortuna eran efectos del caprichoso humor de los dioses. Por lo cual, el hombre era un efecto casual de la naturaleza mitológica. Si bien el mito explicaba este designio aleatorio, el mismo seguía siendo externo al hombre. La cosmovisión de la llustración barre brutalmente la exterioridad de la causa, y la ubica por dentro de las barreras contenedoras del saber. En el afán de encontrarle una respuesta a todo como causa inmanente, "nada absolutamente debe existir fuera, pues la sola idea del exterior es la verdadera fuente del miedo" (Adorno, 2007: 31). Sin embargo, las redes omnipresentes de la razón instrumental se extienden a través de la supuesta conexión con lo absoluto. Indudablemente "pareciera que dejaríamos de pensar si renunciamos a esa metafísica (...) los filósofos (...) creen precisamente en la razón como una parte del mundo metafísico mismo" (Nietzsche, 2015b: 281), y como 
tal es asumida como un desprendimiento del noúmeno e incuestionable. El hombre a través de la razón instrumental logró enseñorearse. La razón es la unidad del yo-pienso, aquel sujeto que tiene la posesión de la palabra para denominar a todo objeto que se topa en su camino. La destrucción de esta unidad es una ruptura decantada ante las crecientes fisuras disimuladas. La razón de la ilustración es aquella que volteó al mito y se burló de la poetización de las explicaciones de antaño tomando a la unidad que la compone como un todo indisoluble. Es como afirma Nietzsche: "los filósofos creen otorgar un honor a una cosa cuando la deshistorizan (...) cuando hacen de ella una momia" (Nietzsche, 2010: 51), y la razón momificó al conocimiento volviéndolo todo estable y constante. De esa forma se conoce sólo lo que "la razón ya ha puesto en el objeto" (Adorno, 2009: 41), como Kant lo traducía en los juicios sintéticos a priori. La mitologización de la razón responde a una vuelta a la absolutización de lo dado. La necesidad de poner una contención al saber y encerrarlo sobre sí mismo deviene en una razón de la llustración idéntica a la mitología denostada. La razón habla el mismo lenguaje que el mito respondiendo a las mismas necesidades y vicisitudes sobre todo a pesar del hombre.

\section{2-Dios murió pero pervive en sus sombras.}

Atónitos quedaron los hombres cuando escucharon resonar en las palabras del hombre loco "<<i Dónde se ha ido Dios? >>", gritó, $<<$ iOs lo voy a decir! ¡Lo hemos matado vosotros y yo! ¡Todos nosotros somos sus asesinos!>>" (Nietzsche, 2014: 161) . Rodeados de hombres que negaban la existencia de Dios, el presagio resultaba vacío y pestilente. Sin embargo, el convencimiento de esos hombres ante la inexistencia del Supremo ponía en cuestión cómo habían sido constituidas las nuevas fronteras del tránsito confortable. Por eso la pregunta del hombre loco "<<íno estamos vagando como a través de una nada infinita? >>" (Nietzsche, 2014: 161), la cual es la apertura al interrogante que la humanidad a intentado acallar erigiéndose como un nuevo Dios. Así como Napoleón puso sobre sí mismo la corona para autoproclamarse emperador, el hombre lo hizo con la propia razón clausurando los interrogantes pertinentes sobre la existencia y el devenir.

La intensa búsqueda de una razón última terminó con el asesinato de Dios. El hombre redactó el acta de defunción cuando no halló rastros de una existencia plena $y$, así, hizo de este mundo un lugar de eterna tautología. Sin embargo, Occidente siempre sintió aversión por el devenir puesto que cuestionaba el "monótono-teísmo". Pavorosos -los hombres- 
encontraron cobijo bajo entidades eternas e inmóviles. Tras ese cielo estable se construyeron diferentes murallas conceptuales. Siendo Dios la más alta, imbatible y eterna. Sin embargo, un día el eterno murió y nadie vertió lágrimas por la pérdida. La ausencia no percibida fue producto de las propias sombras de Dios. Si bien Dios ha muerto, los hombres tienen tal necesidad de lo divino que en sus sombras sigue apareciendo constantemente. La llustración denostó la metafísica religiosa pero en el lugar vacante ubicó a la Razón.

Para Heidegger la sentencia de la "muerte de Dios" es el punto final de la historia del platonismo. No hay más allá, todo se resuelve acá. Esta pérdida del sentido se encuentra en el lugar de la apertura a la larga agonía de occidente inaugurada en el movimiento llamado nihilismo. El hombre nihilista "juzga que el mundo tal y como es no debería ser, y que el múndo tal y como debería ser no existe" (Nietzsche, 2015b: 250). La pérdida de valor propiamente dicho de todos los valores es el síntoma de la muerte de Dios, y sin embargo, el mundo sigue girando y por arte de la propia estabilidad genera nuevos valores. Ese ida y vuelta de creación de nuevos dioses también se encuentra en la etapa nihilista. Nuevos y viejos valores no rompen la cadena del nihilismo. La crónica de la decadencia ante la necesidad constante de erigir valores. Dios muere pero pervive en la Razón. Ante ello Heidegger propone que "el pensar sólo comienza cuando hemos experimentado que la razón, tan glorificada durante siglos, es la más tenaz adversaria del pensar" (Heidegger, 2010: 198).

\section{3.- La voluntad de crear a un Dios desenmascarado.}

El pensamiento negativo nietzscheano, tal como lo califica Cacciari, es una respuesta afirmativa a la producción de sentido ante la nihilista sentencia de una ausencia de fundamento último. Había quedado presente la idea de un orden, a pesar de la carencia de sentido. Cacciari afirma que gracias a la unidad ficcional del sujeto esa idea estructurante de una arquitectura de sentido es posible (Cacciari, 1982: 67). Admitiendo la falsedad del mundo podemos jugar en la configuración de un orden en la naturaleza a pesar de la contingencia. Esto significa irrumpir en la clásica relación de sujeto-objeto, donde el segundo es reductible a un dato inmediato de acuerdo a la valoración del primero. Este razonamiento lógico sin movimiento es a lo que se opone Nietzsche. Como lo hemos mencionado anteriormente, la ficción 
es una carta afable no sólo a modo de necesidad sino como herramienta heurística ante el mundo deviniente. Si "el lenguaje debe resignarse a ser cálculo, y para conocer la naturaleza, renunciar a la pretensión de asemejarse a ella" (Adorno, 2007: 33), se condena al hombre a una soledad ensimismada en la nada. Aunque "la experiencia fundamental consiste en que el carácter del mundo en devenir no sería formulable" (Cacciari, 1982: 68) y, ante esa sentencia, sería incomunicable un lenguaje sin reglas de juego claras. Nietzsche, al inaugurar el mundo del error, no lo hace en contraposición de uno verdadero. Ya que la verdad puede ser entendida como el proceso seguido a los fines de volver el mundo formulable y comunicable. La apariencia es una de las tantas máscaras que se asumen en el baile del devenir donde la contingencia marca el ritmo. Nuevamente, caemos en la misma indagación ¿Cómo podemos conocer? ¿ Si todo es contingente se puede captar una estancia de ese devenir constante? ¿Si no hay un fondo de que se puede tener una certeza? Cacciari, ávido lector de los Fragmentos Póstumos, nos invita a pensar que, sin una sistematización de la secuencia del devenir, sería imposible la vida. El proceso de logicización del mundo responde a la funcionalidad de comprensión y tránsito del individuo ante el escenario cambiante. Es como afirma Nietzsche: "el mundo se nos aparece lógico porque previamente nosotros lo hemos logificado" (Nietzsche, 2015b: 279). Por lo tanto, la lógica no puede ser absoluta y cerrada sino una estancia abierta a fluctuaciones y modificaciones. Siguiendo esta dinámica, "el lenguaje no es una estructura formal a priori, eterna, inmutable e independiente de su historia" (Meca, 2018: 131) sino que está anclada a una determinada situacionalidad formal de un tiempo espacial concreto.

La voluntad de poder activa es la que da lugar a ésta lógica del entendimiento humano. Se deja a un lado la clásica alusión de poder como unidad sintetizadora, ya que la síntesis es una vuelta al mundo de las esencias verdaderas. En tanto,"el proceso de logicización (...) es infinito precisamente porque dicho conflicto es in-finito"(Cacciari, 1982: 74). Por dicho motivo, debemos asegurarnos de desasnar todo tipo de unidad verdadera reponiendo una ficcional y aparente como única existente. El andar sobre el abismo es un recorrido errante y divergente. La vida peligrosa y azarosa propuesta tiene lugar gracias a un dispositivo, con diferentes valencias, como el olvido.

El olvido posibilita la existencia de la verdad, entendida ésta como máscara. No recordar cómo se han creado las metáforas le permite al individuo afianzar los vínculos mismos sobre una estructura logicizante. El hombre, al asumirse como la medida de todas las cosas, corre el riesgo de caer en el error de que las cosas se les presentan como objetos puros. 
Sin embargo, también el olvido significa "cerrar de vez en cuando las puertas y la ventana de la conciencia" (Nietzsche, 2012a: 84), una fuerza activa que posibilita el desarrollo de un espacio vital deshaciéndose del peso de los valores estancos. Aunque también ese dispositivo es condenado como lo hemos visto anteriormente por posibilitar la abstracción de los conceptos respondiendo a una petrificación reactiva sobre la capacidad creadora del hombre.

Lejos de ensayar una propuesta acabada, el recorrido por esta instancia del pensamiento nietzscheano nos suscita interrogantes que invitan a proponer una contracara. El mundo está en constante devenir y la "realidad es siempre sólo una simplificación para fines prácticos o un engaño a causa de órganos bastos, o una diferencia en el tempo del devenir" (Nietzsche, 2012a: 251). Quizás necesitamos un Dios develado, dónde por momentos olvidemos el origen de su status antropológico y, por otros, rehuyamos de ese mismo dispositivo que nos aleja de la actividad volitiva. Nunca perdiendo de vista que "la creencia en la permanencia, en la duración, en lo incondicionado, no es la creencia que es más verdadera, sino la que es más útil" (Vaihinger, 1996: 61).

\section{Bibliografía}

Adorno, Theodor y Horkheimer, Max (2007) Dialéctica de la llustración, Ediciones Akal, Madrid.

Cacciari, Massimo (1982) Krisis. Ensayo sobre la crisis del pensamiento negativo de Nietzsche a

Wittgenstein, Siglo XXI Editores, México.

Cano, Germán (2001) Nietzsche y la crítica de la modernidad, Editorial 
Biblioteca Nueva, Madrid.

Cragnolini, Mónica (1998) Nietzsche, camino y demora, Editorial Universitaria de Buenos Aires, Buenos Aires.

Cragnolini, Mónica (2016) Moradas nietzscheanas: del sí mismo, del otro y del "entre", Ediciones La Cebra, Buenos Aires.

Deleuze, Gilles (2016) "Nietzsche y la filosofía", Editorial Anagrama, Barcelona.

Foucault, Michel (2014) Nietzsche, la genealogía, la historia, Pre-Textos, Valencia.

García Gual, Carlos (2007) Introducción a la mitología griega, Alianza, Madrid.

García Morente, Manuel (2013) Lecciones preliminares de filosofía, Editorial Losada, Buenos Aires.

Heidegger, Martin (2010) Caminos de bosque, Alianza Editorial, Madrid, Heidegger, Martin (2014) Nietzsche, Editorial Ariel, Barcelona.

Kant, Immanuel (1999) Prolegómenos a toda metafísica futura que haya de poder presentarse como ciencia, Ediciones Itsmo, Madrid.

Kant, Immanuel (2010) Crítica de la razón pura, Editorial Gredos, Madrid.

Maresca, Silvio (1997) Friedrich Nietzsche: Verdad y tragedia, Alianza Editorial, Buenos Aires.

Nietzsche, Friederich (2010) Crepúsculo de los ídolos, Alianza Editorial, Madrid, España.

Nietzsche, Friedrich (2012a) La genealogía de la moral, Alianza Editorial, Buenos Aires.

Nietzsche, Friedrich (2012b) Sobre verdad y mentira, Miluno Editorial, Buenos Aires.

Nietzsche, Friedrich (2014a) Así habló Zaratustra, Alianza Editorial, Buenos Aires.

Nietzsche, Friedrich (2014b) La gaya ciencia, Ediciones Akal, Madrid.

Nietzsche, Friedrich (2015a) Aurora. Pensamientos sobre los prejuicios morales, Biblioteca Nueva, Madrid.

Nietzsche, Friedrich (2015b) Fragmentos postumos (1885-1889). Volumen IV, Editorial

Tecnos, Madrid.

Nietzsche, Friedrich (2016) Obras completas: Volumen I. Escritos de 
juventud, Editorial

Tecnos, Madrid.

Nietzsche, Friedrich (2017) Obras completas: Volumen II. Escritos filológicos, Editorial

Tecnos, Madrid.

Sánchez Meca, Diego (1989) En torno al supperhombre: Nietzsche y la crisis de la modernidad, Editorial Anthropos, Barcelona.

Sánchez Meca, Diego (2018) Nietzsche, la experiencia dionisíaca del mundo, Editorial

Tecnos, Madrid.

Vaihinger, Hans (1996) La voluntad de ilusión en Nietzsche, Editorial Tecnos, Madrid.

Vattimo, Gianni (2012) Introducción a Nietzsche, Editorial RBA, Barcelona.

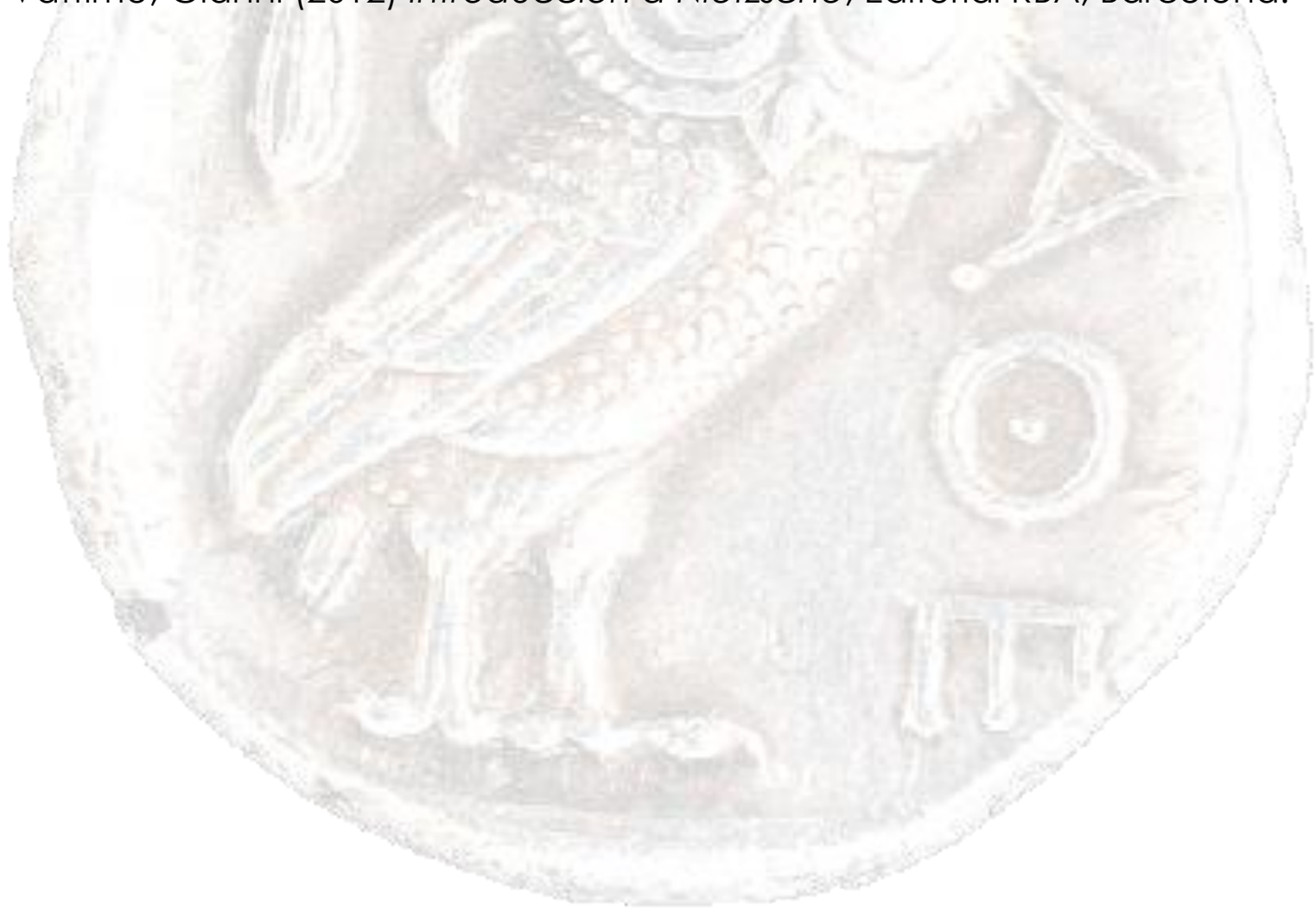

